Article

\title{
Ternary Blended Binder for Production of a Novel Type of Lightweight Repair Mortar
}

\author{
Milena Pavlíková ${ }^{1}$, Lucie Zemanová ${ }^{1}$, Martina Záleská ${ }^{1}$, Jaroslav Pokorný ${ }^{1}$, Michal Lojka ${ }^{2}$, \\ Ondřej Jankovský ${ }^{2}$ and Zbyšek Pavlík ${ }^{1, *(D)}$ \\ 1 Department of Materials Engineering and Chemistry, Faculty of Civil Engineering, Czech Technical \\ University in Prague, Thákurova 7, 16629 Prague 6, Czech Republic; milena.pavlikova@fsv.cvut.cz (M.P.); \\ lucie.zemanova@fsv.cvut.cz (L.Z.); martina.zaleska@fsv.cvut.cz (M.Z.); jaroslav.pokorny@fsv.cvut.cz (J.P.) \\ 2 Department of Inorganic Chemistry, Faculty of Chemical Technology, University of Chemistry and \\ Technology, Technická 5, 16628 Prague 6, Czech Republic; michal.lojka@vscht.cz (M.L.); \\ ondrej.jankovsky@vscht.cz (O.J.) \\ * Correspondence: pavlikz@fsv.cvut.cz; Tel.: +420-224-354-371
}

Received: 20 February 2019; Accepted: 22 March 2019; Published: 26 March 2019

\begin{abstract}
The goal of the paper was development and testing of a novel type of ternary blended binder based on lime hydrate, metakaolin, and biomass ash that was studied as a binding material for production of lightweight mortar for renovation purposes. The biomass ash used as one of binder components was coming from wood chips ash combustion in a biomass heating plant. The raw ash was mechanically activated by grinding. In mortar composition, wood chips ash and metakaolin were used as partial substitutes of lime hydrate. Silica sand of particle size fraction $0-2 \mathrm{~mm}$ was mixed from three normalized sand fractions. For the evaluation of the effect of biomass ash and metakaolin incorporation in mortar mix on material properties, reference lime mortar was tested as well. Among the basic physical characterization of biomass ash, metakaolin and lime hydrate, specific density, specific surface, and particle size distribution were assessed. Their chemical composition was measured by X-Ray fluorescence analysis (XRF), morphology was examined using scanning electron microscopy (SEM), elements mapping was performed using energy dispersive spectroscopy (EDS) analyser, and mineralogical composition was tested using X-Ray diffraction (XRD). For the developed mortars, set of structural, mechanical, hygric, and thermal properties was assessed. The mortars with ternary blended binder exhibited improved mechanical resistance, lower thermal conductivity, and increased water vapor permeability compared to the reference lime mortar. Based on good functional performance of the produced mortar, the tested biomass ash could potentially represent a novel sustainable alternative to other pozzolans commonly used in construction industry. Moreover, reuse of biomass ash in production of building materials is highly beneficial both from the environmental and economic reasons especially taking into account circular economy principles. The ternary blended binder examined in this paper can find use in both rendering and walling repair mortars meeting the requirements of culture heritage authorities and technical standards.
\end{abstract}

Keywords: biomass combustion; ternary blended binder; lightweight mortar; pozzolanic activity; functional properties

\section{Introduction}

Non-hydraulic or sub-hydraulic mortars were used from ancient times until the early 19th century [1]. Nevertheless, first attempts to use hydraulic mortars have been already recognized in Greek and Roman periods [2]. From the half of 19th century, the natural and later synthetic hydraulic lime was used. After the first cement was discovered in the first half of 19th century, cement becomes 
prevailing binder of construction industry [2,3]. Starting from the beginning of 20th century, with the expansion of Portland cement (PC) production, lime plasters were replaced with cement plasters or cement-lime plaster. As lime was used for walling and rendering of buildings for centuries, lime-based plasters are one of the main components of a significant number of old buildings [4-7]. Presently, the application potential of lime mortars is reduced due to the intensive use of PC. On the other hand, cement-base materials possess low water vapor transmission rate [8,9]. Moreover, the use of hydraulic binders in repair mortars has been associated with compatibility problems due to their high strength, stiffness, and low vapor permeability [10-12]. It is generally accepted that the PC used in mortars for conservation and repair of historical buildings was a wrong choice, as renovated structures were often associated with the structural, hygrothermal, and other building pathology problems [13,14]. The culture heritage authorities put emphasis on the use of traditional building materials and techniques in the preservation of built heritage [15-17]. Therefore, lime-based mortars have been used for this purpose in order to achieve the required compatibility with the originally used materials $[18,19]$. Unfortunately, lime based mortars possess some disadvantageous properties, such as low mechanical resistance and susceptibility to harmful water action. This is a serious problem especially for masonry mortars, whereas adherence behavior, shrinkage and color should be considered in designing rendering mortars. Also salt crystallization, hygroscopicity and hydration are among disruptive factors negatively affecting the durability of lime-based mortars [20,21]. Besides that, building practice impose demands on a complex hygrothermal performance of mortars for repair purposes what take into consideration application of lightweight materials that can partially improve thermal behavior of renovated buildings.

In this context, blended mortars represent alternative as they are able to combine the advantages of both aerial lime and hydraulic binders. Based on literature review, the most-studied mortars were those based on lime-cement blends [22-25]. However, use of Portland cement in renewal of historical masonry is strictly forbidden by culture heritage authorities due to its serious incompatibility with original materials that caused in recent restoration inventions significant failures and accelerated the damage of the restored monuments [11].

Instead of Portland cement, materials rich in amorphous silica and/or alumina find use as components of lime blends. It is in accordance with composition of mortars produced by early civilizations that used ceramic and volcanic dust to improve the properties and durability of lime mortars. These materials are called pozzolans, and when appropriately milled react in the presence of water with $\mathrm{Ca}(\mathrm{OH})_{2}$ and form hydraulic products having improved durability characteristics [26]. Pozzolans are of the natural origin (diatomite, zeolite, pumice, etc.) or are produced artificially, for example by thermal processing (metakaolin, perlite). Pozzolans are also by-products of coal and agricultural products combustion (coal fly ash, rice husk ash, pam ash, sugar cane ash, etc.). The cement-pozzolan mortars were intensively studied during last 30 years [27-29]. On the other hand, studies on the use of pozzolans in lime-based masonry or rendering mortars are relatively rare. Sala et al. [30] analyzed properties of lime mortar with natural pozzolan coming from the complex of Monti Sabatini (Rome, Italy). The reported tests clearly showed increase in the mortar strength with the addition of pozzolana. Pavia and Aly [31] studied hydrated lime mortars with rice husk ash and ground granulated blast furnace slag. Both mineral admixtures increased mortars strength with little impact on hygric properties. Ulukaya and Yuzer [32] investigated crushed brick-lime mortars. They observed pozzolanic activity of crushed bricks that resulted in a significant improvement of mortar mechanical properties. Stefanidou [33] used two natural pozzolans in combination with lime for production of repair mortars. Based on the above given survey it can be summarized, the use of lime and pozzolans blends in composition of repair mortars is indispensable for achieving their sufficient mechanical resistance and durability.

In recent decades, there has been worldwide increased awareness of the used of pozzolanic materials in production of materials for construction industry. Nevertheless, specific attention must be paid to renewable mineral admixtures and materials that were formerly considered as waste. 
As building industry is big consumers of natural resources that are used especially for concrete, cement, and lime production, their partial substitution by any suitable eco-efficient material is highly positively appreciated. Therefore, the biomass ash coming from wood chips combustion was studied in this paper as an active eco-efficient mineral admixture in repair mortar based on lime hydrate as the main binder. The potential of the use of biomass ash coming from combustion of different agricultural products as pozzolanic material was proved recently by several research studies conducted on the use of biomass ash as partial PC substitution in mortar and concrete mix design [34-36]. In [34] the authors applied biomass ash coming from wood chips ash production in composition of cement mortar. The strength activity index was high for all examined materials what proved the wood chips ash pozzolanity. However, based on our previous research conducted on biomass ashes, one must always consider origin, chemical and physical parameters of the particular biomass ash before its use as pozzolan.

The other pozzolan used in ternary blended binder was metakaolin, because of its high pozzolanity and proved benefits of its use in lime mortars [37,38]. The pozzolanic activity of metakolin evaluated, e.g., Bakolas et al. [39]. Based on pozzolanic activity tests and assessed physicomechanical characteristics of lime-metakaolin pastes, the compounds formed within the pozzolanic reaction were $\mathrm{CSH}$ and $\mathrm{C}_{2} \mathrm{ASH}_{8}$. Moreover, the calcium hydroxide consumption was higher as the initial dosage of metakaolin in paste increased. Aggelakopoulou et al. [40] studied properties of lime-metakaolin mortar for the restoration of historical masonry. Authors reported on the increased static modulus of elasticity, compressive and flexural strength, with the increased metakaolin/lime ratio in mortar mix.

The novelty of the paper lies in a unique combination of biomass ash and metakaolin in composition of ternary blended binder for production of repair mortars. Based on literature survey given above, both these materials proved their pozzolanic character and applicability in cement-based composites. Moreover, metakaolin found its use also in lime mortars for repair and renovation of historical buildings. In this respect, their combined use represents innovative solution for design and development of a novel type of repair mortar that maintained excellent properties of lime mortars and possessed improved mechanical resistance and durability. Besides that, the reuse of biomass ash in production of construction materials brings both economic and environmental benefits. In this respect, the novel repair mortar can be considered as a cost effective material that can be produced in more sustainable way than most of mortars already used in building practice.

\section{Materials and Methods}

\subsection{Materials and Samples Preparation}

The biomass ash (BA) was obtained from Plzeň heating plant, Plzeň, Czech Republic. The BA examined in this work was a product of wood chips combustion and was used in mortar mix as a part of blended binder. Another binder component was commercially produced metakaolin Mefisto K05 (ČLUZ a.s., Nové Strašecí, Czech Republic). As a primary binder, lime hydrate coming from lime kiln Čertovy schody a.s., Tmaň, Czech Republic, was used. As aggregate, silica sand of fraction 0-2 mm was used. It is a product of Filtrační písky, spol. s r.o., Chlum u Doks, Czech Republic and it was mixed from three fractions. The weight ratio of sand fractions was 1:1:1. The reference lime mortar $\left(\mathrm{M}_{\text {ref }}\right)$ was tested as well. The composition of studied materials is summarized in Table 1.

Table 1. Composition of studied mortars, mass (g). BA: biomass ash.

\begin{tabular}{ccccccc}
\hline Mortar Mix & Lime Hydrate & BA & Metakaolin & Silica Sand & Water & w/b (-) \\
\hline$M_{\text {ref }}$ & 1350 & - & - & $3 \times 1350$ & 1350 & 1.0 \\
MBAM & 643 & 578 & 129 & $3 \times 1350$ & 1202 & 0.9 \\
\hline MBAM stands for mortar with ternary based binder based of lime hydrate, biomass ash and metakaolin.
\end{tabular}

In both mortar mixes, the binder/aggregate ratio was $1 / 3$. The water/binder ratio was high as we planned to developed mortars of high porosity what can be simply achieved by a higher amount 
of batch water. The water/binder ratio was adjusted to get a similar consistency of both mortars. It was verified by flow table test. The value of spreading was 160/160 mm. As BA increased mortar workability, the water/binder ratio was decreased in MBAM mortar.

The casted specimens were rectangular prisms having dimensions of $40 \mathrm{~mm} \times 40 \mathrm{~mm} \times 160 \mathrm{~mm}$, cubes of side $100 \mathrm{~mm}$, and circular flat specimens with diameter of $100 \mathrm{~mm}$ and thickness of $20 \mathrm{~mm}$. Before the particular tests, they were stored in a humidity of approx. $98 \%$ and temperature $(23 \pm 2){ }^{\circ} \mathrm{C}$ for 28 days or 365 days respectively. During curing, the specimens were placed on a steel grid in order to allow their carbonation.

\subsection{Characterization of $B A$ and Metakaolin}

For BA and metakaolin, specific density and Blaine specific surface were measured. The specific density was tested using a Pycnomatic ATC (Thermo Scientific, Milan, Italy). Blaine specific surface was assessed by a Blaine device [41].

For the determination of pozzolanic activity of BA and metakaolin, Chapelle test was used [42].

Chemical composition of BA and Mefisto K05 was measured by X-ray fluorescence (XRF) using Axios sequential WD-XRF spectrometer (PANalytical, Almelo, The Netherlands).

Morphology of binder constituents was studied by scanning electron microscope (TESCAN Lyra 3, Tescan Brno, s.r.o., Brno, Czech Republic) equipped with a FEG electron source. Energy dispersive spectroscopy (EDS) was performed with the analyzer X-MaxN, SDD detector (Oxford instruments, High Wycombe, UK) and AZtecEnergy software (Oxford instruments) to determine the chemical composition.

X-ray diffraction (XRD) was performed on Bruker D8 Discoverer (Bruker AXS GmbH, Karlsruhe, Germany) powder diffractometer with parafocusing Bragg-Brentano geometry at room temperature using $\mathrm{CuK}_{\alpha}$ radiation [34].

The particle size distribution was tested using an apparatus Analysette 22 Micro Tec plus (Fritsch, Idar-Oberstain, Germany) working on a laser diffraction. The device allows identification of particles having size from $0.08 \mu \mathrm{m}$ to $2 \mathrm{~mm}$.

\subsection{Methods of Testing Hardened Mortar Samples}

The tests conducted were aimed at the assessment of structural parameters, mechanical resistance, hygrothermal performance and simultaneous thermal analysis (STA). In addition to the tests conducted for 28 days samples, measurement of basic structural and mechanical parameters was performed also for 365 days samples. The overview of the experimental program reporting type of test, maturation time and number of specimens is given in Table 2.

Table 2. Overview of the experimental campaign conducted for hardened mortar samples.

\begin{tabular}{ccc}
\hline Test & Maturation Time (days) & Number of Specimens \\
\hline Bulk density & 28,365 & 5 \\
Specific density & 28,365 & 5 \\
Open porosity & 28,365 & 5 \\
Pore size distribution & 28 & 2 \\
Flexural strength & 28,365 & 3 \\
Compressive strength & 28,365 & 6 \\
Young's modulus & 28,365 & 5 \\
Water absorption coefficient & 28 & 5 \\
Saturation moisture content & 28 & 5 \\
Apparent moisture diffusivity & 28 & 5 \\
Water vapor permeability & 28 & 5 \\
Water vapor diffusion coefficient & 28 & 5 \\
Water vapor resistance factor & 28 & 5 \\
Volumetric heat capacity & 28 & 5 \\
Thermal conductivity & 28 & 5 \\
simultaneous thermal analysis (STA) & 28 & 2 \\
\hline
\end{tabular}


Among fundamental structural properties of researched mortars, bulk density, specific density, and total open porosity were tested. Before these tests, the specimens were dried in a vacuum drier at $60{ }^{\circ} \mathrm{C}$. The specific density $\rho_{s}\left(\mathrm{~kg} / \mathrm{m}^{3}\right)$ was measured using helium pycnometry. The bulk density $\rho_{b}\left(\mathrm{~kg} / \mathrm{m}^{3}\right)$ of mortar specimens was determined according to the EN 1015-10 [43] using gravimetric method. The expanded combined uncertainty of the bulk density test was $1.2 \%$. The total open porosity $\psi(\%)$ was calculated from the known bulk density and matrix density values with combined uncertainty of $1.7 \%$ [34].

As also pore size affects material performance from the mechanical resistance and hygrothermal performance point of view, pore size distribution was measured using mercury porosimetry (Pascal 140 and Pascal 440, Thermo, Milan, Italy). The typical specimens mass was about $0.9 \mathrm{~g}$.

For the assessment of mechanical resistance of mortars with admixing of BA and metakaolin, their flexural strength $f_{f}(\mathrm{MPa})$, compressive strength $f_{c}(\mathrm{MPa})$, and dynamic Young's modulus $E_{d}(\mathrm{GPa})$ were tested. The strength tests were conducted according to the standard EN 1015-11 [44] on $40 \mathrm{~mm}$ $\times 40 \mathrm{~mm} \times 160 \mathrm{~mm}$ prisms and their rests from flexural strength testing. The relative expanded uncertainty of strength tests was $1.4 \%$. The Young's modulus $E_{d}(\mathrm{GPa})$ was tested using a DIO 562 apparatus (Starmans Electronics s.r.o., Prague, Czech Republic). The expanded combined uncertainty of this test method was $5.6 \%$. Based on the compressive strength data, strength activity index (SAI) was calculated [45]. It is generally accepted, a material can be considered as pozzolan if SAI $\geq 75 \%$ [46].

As masonry and rendering mortars usually suffer from excessive moisture presence, ability of studied mortars to transport water and water vapor was tested. Water absorption coefficient $A_{w}\left(\mathrm{~kg} /\left(\mathrm{m}^{2} \mathrm{~s}^{1 / 2}\right)\right)$ and saturated moisture content $w_{\text {sat }}\left(\mathrm{kg} / \mathrm{m}^{3}\right)$ were measured in free water intake experiment [47] that was conducted according to the standard EN 1015-18 [48]. Apparent moisture diffusivity $\kappa\left(\mathrm{m}^{2} / \mathrm{s}\right)$ was calculated as originally proposed by Kumaran [49]. The expanded combined uncertainty of the water absorption test was $2.3 \%$, of the saturated moisture content test it was $1.4 \%$ and that of the apparent moisture diffusivity test was $6.6 \%$.

Water vapor transport parameters were tested under isothermal conditions using cup method. The water vapor transmission test was performed following standard ISO 12572 [50] in the both dry-cup and wet-cup arrangements. Details on the measurement conditions can be found in [34]. Based on the cup test, the water vapor permeability $\delta(\mathrm{s})$, the water vapor diffusion coefficient $D$ $\left(\mathrm{m}^{2} / \mathrm{s}\right)$, and the water vapor resistance factor $\mu(-)$ were assessed. The expanded combined uncertainty of the cup test was for $1.4 \%$ for $\delta, 1.6 \%$ for $D$, and 2.1 for $\mu$.

Because renders have a significant effect on the thermal performance of buildings, thermal transport and storage parameters of studied mortars were tested. For the dry and fully water saturated thermal conductivity $\lambda(\mathrm{W} /(\mathrm{m} \cdot \mathrm{K}))$ and volumetric heat capacity $c_{v}\left(\mathrm{~J} /\left(\mathrm{m}^{3} \cdot \mathrm{K}\right)\right)$ measurement, ISOMET 2114 (Applied Precision) was used. The expanded combined uncertainty of the thermal conductivity and volumetric heat capacity tests was $1.7 \%$.

Thermal behavior of tested mortars was analyzed by Simultaneous thermal analysis (STA) on a Linseis STA PT1600 apparatus (Linseis Messgeraete GmbH, Selb, Germany).

Mortar specimens were also studied using Dino-Lite digital optical microscope (Dino-Lite/IDCP B.V., Naarden, The Netherlands) with resolution of $5 \mathrm{Mpx}$.

\section{Results and Discussion}

Basic structural parameters and pozzolanic activity of binder constituents is given in Table 3. For comparison, Blaine fineness and specific density of lime hydrate were also introduced. The lowest Blaine fineness exhibited biomass ash. It was due to its insufficient milling in laboratory contrary to effective milling of commercially manufactured lime hydrate and metakaolin. On the other hand, both mineral admixtures proved their high pozzolanic activity considering the lower limit of $650 \mathrm{mg}$ of $\mathrm{Ca}(\mathrm{OH})_{2} / \mathrm{g}$ of material to be classified as pozzolana active [51,52].

Chemical composition of BA and metakaolin obtained by XRF analysis is given in Table 4, whereas normalized wt.\% values are presented. Biomass ash and metakaolin contained high amount of silica 
and alumina phases what was positive for their presumed use as active mineral admixtures in mortar mix composition. The content of chlorides and sulfates was in both studied materials low, i.e., new resources of soluble salts rising from the use of repair mortar with incorporated BA and Mefisto K05 are avoided, being salt action one of the most often causes of decay of old masonry [53].

Table 3. Physical parameters and pozzolanic activity of binder constituents.

\begin{tabular}{cccc}
\hline Materials & Blaine Fineness $\left(\mathbf{m}^{\mathbf{2}} / \mathbf{k g}\right)$ & Specific Density $\left(\mathbf{k g} / \mathbf{m}^{\mathbf{3}}\right)$ & Pozzolanic Activity $(\mathbf{\%})$ \\
\hline Lime hydrate & 2205 & 2214 & - \\
BA & 798 & 2614 & 1340 \\
Mefisto K05 & 1608 & 2622 & 1967 \\
\hline
\end{tabular}

Table 4. X-Ray fluorescence analysis (XRF) chemical composition, amount (wt.\%).

\begin{tabular}{ccc}
\hline Substance & BA & Mefisto K05 \\
\hline $\mathrm{CuO}$ & 0.01 & - \\
$\mathrm{Na}_{2} \mathrm{O}$ & 0.31 & - \\
$\mathrm{ZnO}$ & 0.11 & - \\
$\mathrm{MgO}$ & 1.18 & 0.44 \\
$\mathrm{Al}_{2} \mathrm{O}_{3}$ & 12.32 & 37.91 \\
$\mathrm{BaO}$ & 0.16 & - \\
$\mathrm{SiO}_{2}$ & 48.72 & 59.41 \\
$\mathrm{P}_{2} \mathrm{O}_{5}$ & 2.63 & - \\
$\mathrm{SO}_{3}$ & 1.24 & - \\
$\mathrm{SrO}$ & 0.07 & 0.03 \\
$\mathrm{Cl}$ & 0.24 & - \\
$\mathrm{ZrO}$ & 0.04 & - \\
$\mathrm{K}_{2} \mathrm{O}$ & 7.56 & 0.81 \\
$\mathrm{CaO}$ & 17.45 & 0.20 \\
$\mathrm{TiO}_{2}$ & 0.82 & 0.51 \\
$\mathrm{~V}_{2} \mathrm{O}_{5}$ & 0.03 & - \\
$\mathrm{PbO}$ & 0.03 & - \\
$\mathrm{MnO}$ & 1.66 & - \\
$\mathrm{Fe}_{2} \mathrm{O}_{3}$ & 5.42 & 0.72 \\
$\sum$ & 100.00 & 100.00 \\
\hline
\end{tabular}

The morphology and elemental distribution maps of BA and metakaolin are apparent from SEM images and EDS mapping in Figure 1. SEM micrographs of BA proved varied morphology; particles had dimensions between $1 \mu \mathrm{m}$ and $50 \mu \mathrm{m}$. These particles often form huge agglomerates. Also their shapes differed. Obtained chemical composition was in good agreement with XRF results: the most represented elements were $\mathrm{C}, \mathrm{O}, \mathrm{Si}, \mathrm{Ca}, \mathrm{K}, \mathrm{Al}, \mathrm{Mg}, \mathrm{Fe}$, and $\mathrm{Na}$. On the other hand, SEM micrographs of Metakaolin showed less agglomerates. Particles had dimensions between $1 \mu \mathrm{m}$ and $10 \mu \mathrm{m}$. EDS confirmed that the major elements present were $\mathrm{O}, \mathrm{C}, \mathrm{Si}, \mathrm{Al}$, and $\mathrm{K}$ in this sample.

Phase composition of BA and metakaolin was analyzed using X-Ray diffraction (XRD) (see Figure 2).

Sample BA was highly crystalline and it contained mainly silicon dioxide (quartz), calcium carbonate (calcite), and also other aluminosilicates. Metakaolin was highly amorphous, but some crystalline phases were detected as well (quartz, mullite, and others).

Particle size distribution of lime hydrate, BA, and metakaolin is graphed in Figures 3 and 4. Metakaolin Mefisto K05 was the finest binder constituent $\left(d_{50}=3.5 \mu \mathrm{m}\right)$ what was in the agreement with its high specific surface. BA milled in laboratory had slightly worse fineness $\left(d_{50}=34.3 \mu \mathrm{m}\right)$ compared to lime hydrate $\left(d_{50}=31.2 \mu \mathrm{m}\right)$. However, it was still acceptable considering the upper limit for pozzolan fineness introduced in EN 450-1 [45].

Photography of prepared samples is shown in Figure 5A. This figure demonstrated that both samples contained minimum cracks or other defects on both macroscales and microscales. In comparison, sample MBAM has even lower amount of defects in comparison to the reference $M_{\text {ref }}$. 
Figure 5B shows micrographs obtained by optical microscopy. In both cases, phases are homogenously distributed, no agglomerates were detected. The color of mortar with incorporated biomass ash was slightly changed compared to the white-beige color of reference mortar. It was bright gray due to the use of biomass ash. For masonry mortar, the color change is not a crucial parameter. On the other hand, for rendering purposes, the gray color of the developed mortar can be beneficially used for sgraffito technique for a facade decoration. Moreover, the color of biomass ash and thus of mortar with ternary based binder can be changed by its thermal treatment.
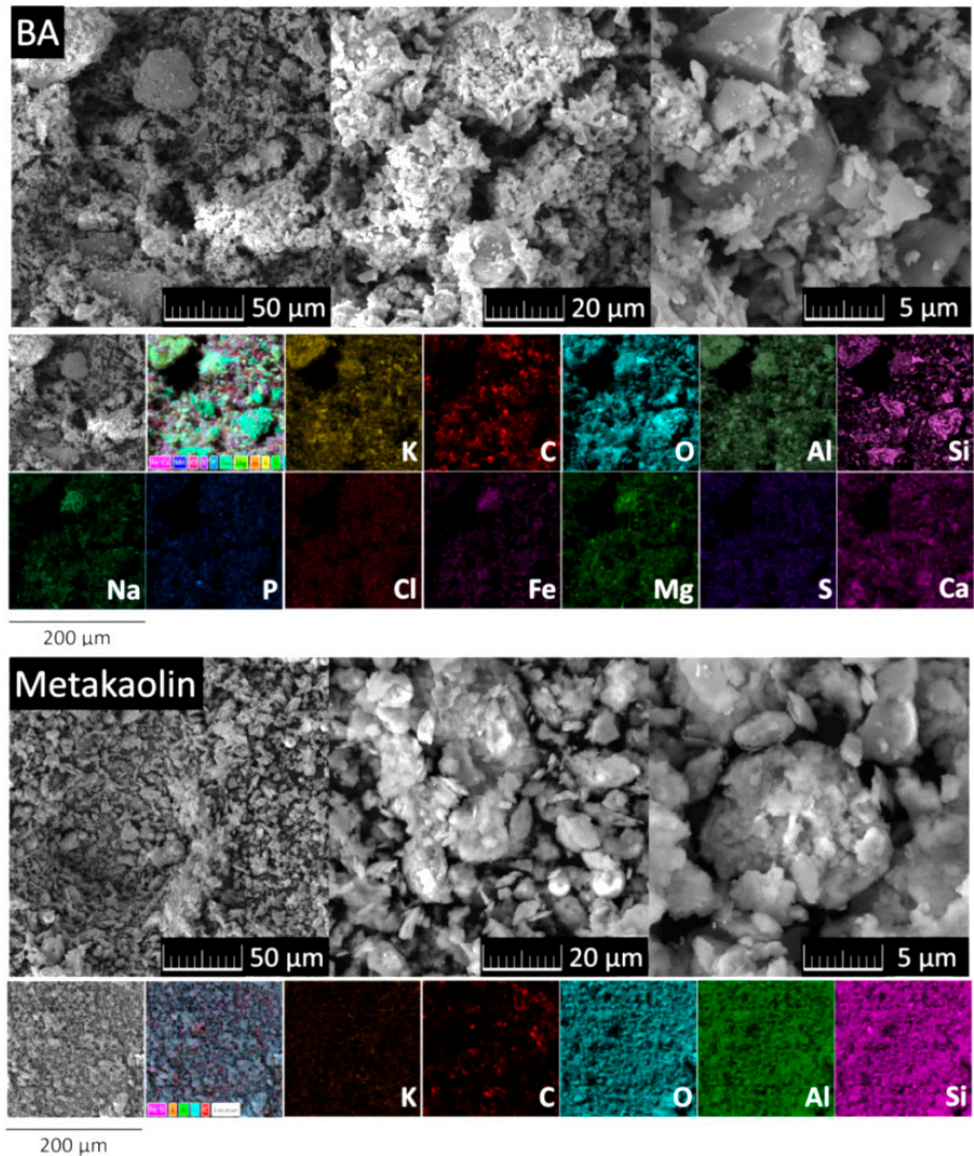

Figure 1. Morphology and elemental distribution maps of BA and metakaolin obtained by scanning electron microscopy energy dispersive spectroscopy (SEM-EDS).

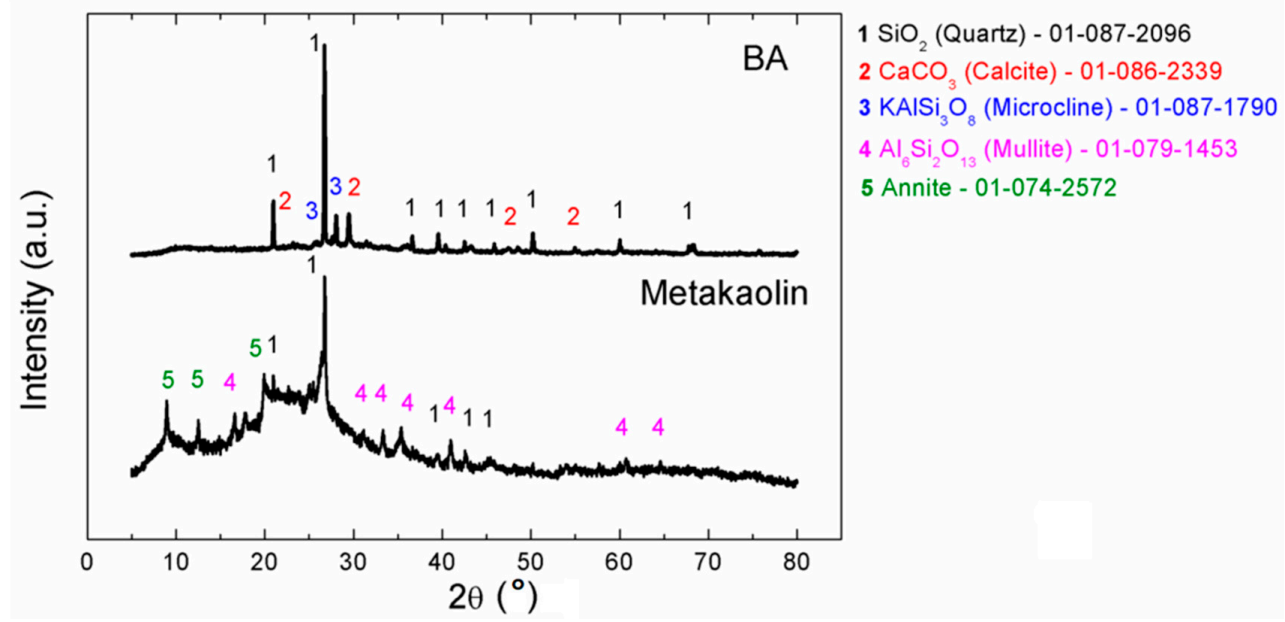

Figure 2. Diffractograms of BA and Metakaolin. 


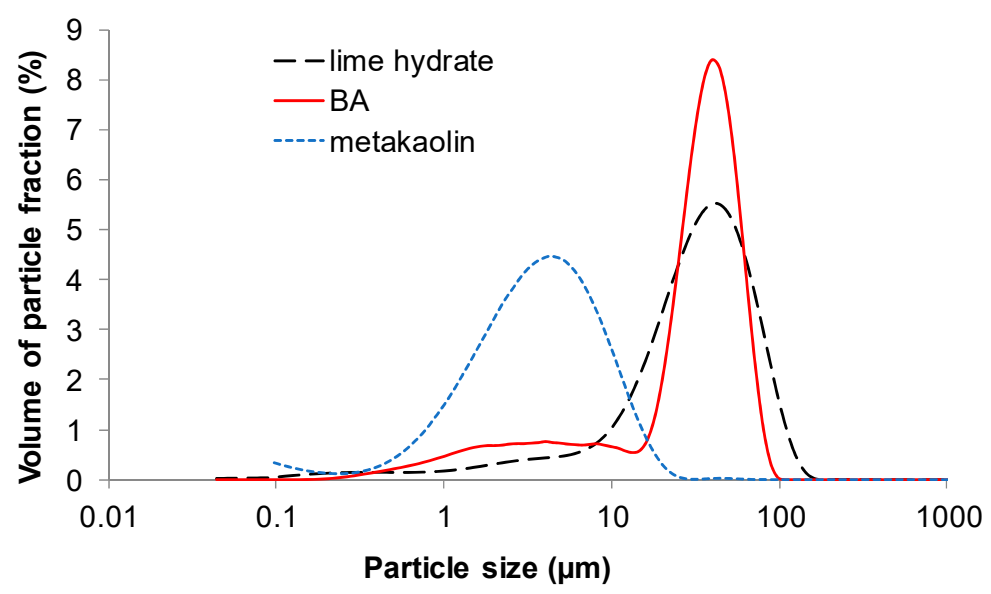

Figure 3. Particle size distribution-distribution curves.

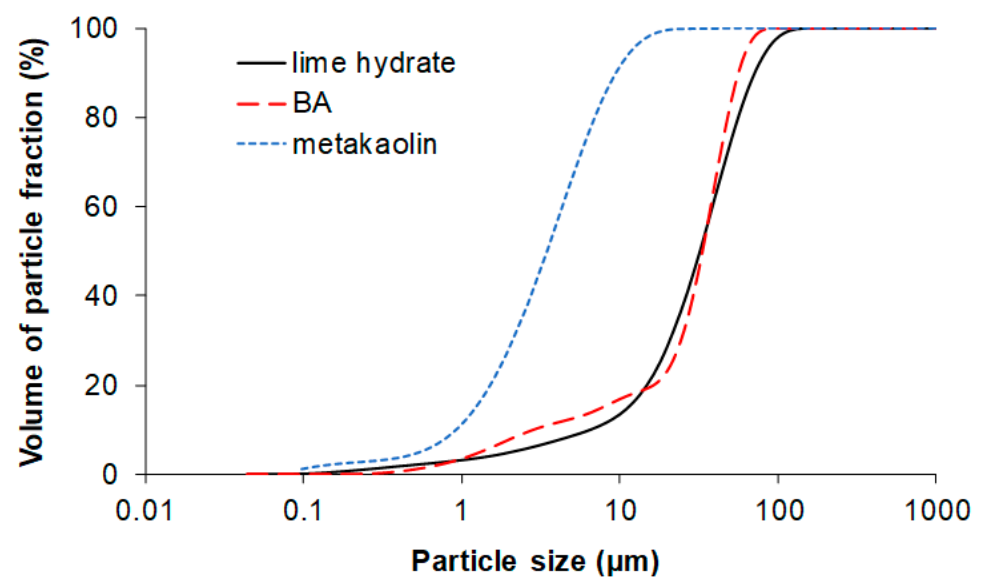

Figure 4. Particle size distribution-cumulative curves.

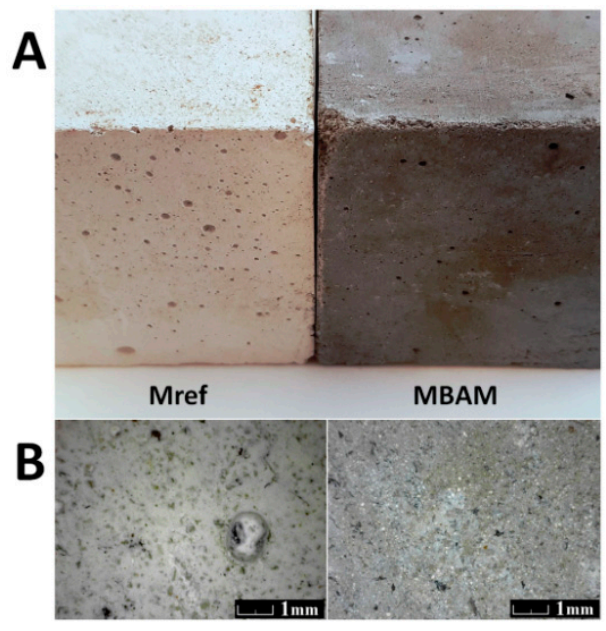

Figure 5. (A) Photography of $M_{\text {ref }}$ (left) and MBAM (right) and (B) optical micrograph of $M_{\text {ref }}$ (left) and MBMA (right).

The presented material parameters of hardened mortars represent average value obtained from the measurement of a specific number of samples studied in the particular research test (see Table 2). The fundamental structural properties of researched mortars are summarized in Table 5. The use of BA and metakaolin resulted in decrease in bulk density and thus significant increase in porosity despite of a lower water/binder ratio of MBAM mortar compared to reference mix. One of the decisive 
parameters of repair mortars is their high porosity that should enable possible salt accumulation and water vapor transmission. According to the WTA-Specifications (International Association for the Science and Technology in Maintenance of Structures and Protection of Monuments) the porosity of repair mortar must be $>40 \%$ [54]. In this respect, the use of ternary blended binder was quite effective and the obtained data proved its applicability in design of rendering and masonry mortars applicable for historical damp and salt contaminated interior or exterior walls.

Table 5. Fundamental structural properties.

\begin{tabular}{|c|c|c|c|c|}
\hline \multicolumn{2}{|c|}{ Materials } & \multirow{3}{*}{$\begin{array}{c}\text { Specific Density } \\
\rho_{\mathbf{s}}\left(\mathbf{k g} / \mathbf{m}^{\mathbf{3}}\right)\end{array}$} & \multirow{3}{*}{$\begin{array}{c}\begin{array}{c}\text { Bulk Density } \boldsymbol{\rho}_{\boldsymbol{b}} \\
\left(\mathbf{k g} / \mathbf{m}^{\mathbf{3}} \mathbf{)}\right.\end{array} \\
1670 \pm 20 \\
1410 \pm 17\end{array}$} & \multirow{3}{*}{$\begin{array}{c}\begin{array}{c}\text { Total Open } \\
\text { Porosity } \boldsymbol{\psi}(\boldsymbol{\%})\end{array} \\
34.7 \pm 0.6 \\
43.6 \pm 0.7 \\
\end{array}$} \\
\hline \multirow{2}{*}{28 days } & $\mathrm{M}_{\mathrm{ref}}$ & & & \\
\hline & MBAM & & & \\
\hline \multirow{2}{*}{$\begin{array}{c}365 \\
\text { days }\end{array}$} & $\mathrm{M}_{\mathrm{ref}}$ & 2580 & $1710 \pm 21$ & $33.7 \pm 0.6$ \\
\hline & MBAM & 2540 & $1475 \pm 18$ & $41.9 \pm 0.7$ \\
\hline
\end{tabular}

Pore size distribution measured by mercury intrusion porosimetry is shown in Figure 6.

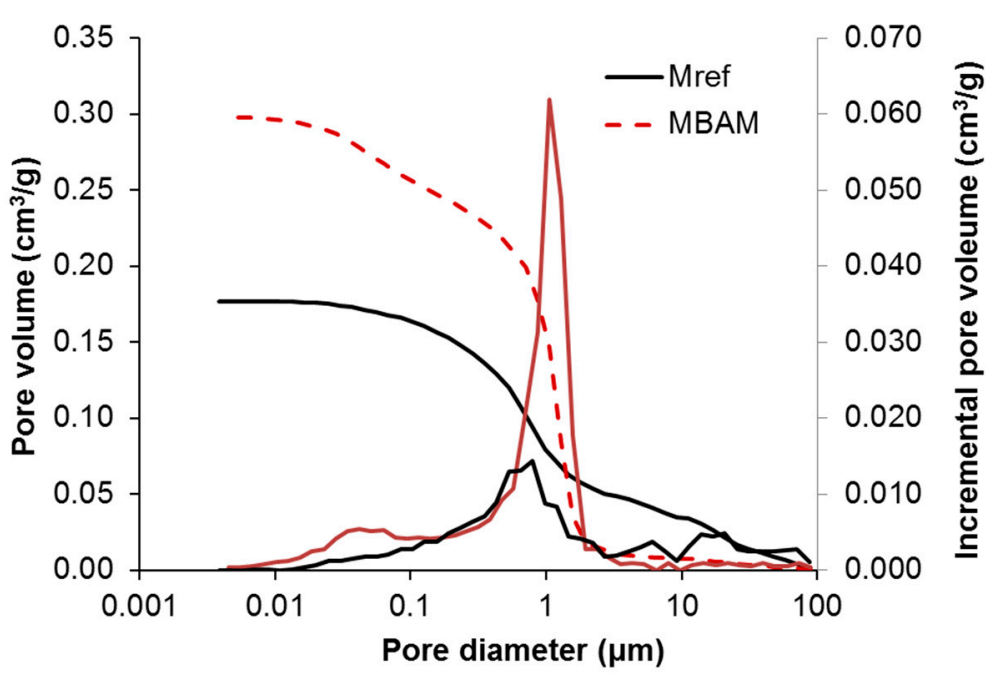

Figure 6. Pore size distribution.

The total porosity assessed by mercury intrusion porosimetry was $43.1 \%$ for MBAM and $32.8 \%$ for $\mathrm{M}_{\text {ref }}$. Considering the mass of tested specimens which was about $0.9 \mathrm{~g}$, the results were in quantitative agreement with those calculated on the basis of specific density and bulk density tests. MBAM had significantly higher volume of pores in the range from $0.01 \mu \mathrm{m}$ to $1.3 \mu \mathrm{m}$. According to IUPAC (International Union of Pure and Applied Chemistry) classification of pore sizes [55], these pore were classified as macropores (large capillaries $>0.05 \mu \mathrm{m}$ ) and mesopores (medium capillaries 0.05-0.01 $\mu \mathrm{m})$. Macropores affected mortar strength and mesopores its transfer properties. On the other hand, reference mortar $\mathrm{M}_{\text {ref }}$ exhibited higher volume of macropores $>1.3 \mu \mathrm{m}$, what was probably the main reason of its lower strength. The volume of small gel capillaries $(<0.01 \mu \mathrm{m})$ was in both studied mortars negligible as these pores are common for hydraulic mortars [56]. In lime mortars are gel pores limited and are formed inside the binder crystal lattice [57].

The mechanical parameters of tested mortars are given in Table 6. In spite of higher porosity of mortar MBAM, its mechanical resistance was higher compared to that of reference mortar $\mathrm{M}_{\text {ref }}$. This feature was apparent for both 28 days and 365 days samples. In this case, the porosity was not only parameter contributing to the mechanical resistance of the developed ternary binder-based mortar. The increase in mechanical resistance we assign to C-S-H and C-S-A-H phases formed within the pozzolanic reaction of metakaolin and biomass ash with lime hydrate as these products are more 
durable and mechanical resistant compared to products of lime hydrate hardening. Quantitatively, values of mechanical parameters obtained for 28 days samples were higher than considered typical for non-hydraulic mortars [58,59] what is promising for mortar use not only for rendering but also for structural (walling) purposes. The value of strength activity index was high, and gave information on great pozzolanic activity of both incorporated mineral admixtures.

Table 6. Mechanical properties.

\begin{tabular}{cccccc}
\hline \multirow{2}{*}{ Materials } & $\begin{array}{c}\text { Compressive } \\
\text { Strength } \boldsymbol{f}_{\boldsymbol{c}} \mathbf{( M P a )}\end{array}$ & $\begin{array}{c}\text { Flexural Strength } \\
\left.\boldsymbol{f}_{f} \mathbf{( M P a}\right)\end{array}$ & $\begin{array}{c}\text { Young's Modulus } \\
\boldsymbol{E}_{\boldsymbol{d}} \mathbf{( G P a )}\end{array}$ & \multirow{2}{*}{ SAI (\%) } \\
\hline \multirow{2}{*}{28 days } & $\mathrm{M}_{\text {ref }}$ & $1.32 \pm 0.02$ & $0.47 \pm 0.007$ & $2.6 \pm 0.15$ & - \\
& MBAM & $1.56 \pm 0.02$ & $0.51 \pm 0.007$ & $2.7 \pm 0.15$ & 118.2 \\
\hline \multirow{2}{*}{365 days } & $\mathrm{M}_{\text {ref }}$ & $1.78 \pm 0.03$ & $0.72 \pm 0.01$ & $2.9 \pm 0.16$ & - \\
& MBAM & $1.98 \pm 0.02$ & $0.75 \pm 0.01$ & $3.0 \pm 0.17$ & 111.2 \\
\hline
\end{tabular}

The parameters characterizing liquid water transport in tested mortars are presented in Table 7. Their values are in agreement with porosity data, i.e., due to the increased total open porosity the water absorption accelerated. This feature is on the one hand positive, as it ensures water transport to areas when evaporation takes place, and on the other hand, it can negatively affect mortars and their substrates durability in the presence of excessive moisture. Therefore, in practical applications, the exterior surface of renderings mortars made of MBAM mortar type must be provided with hydrophobic additive or the inner hydrophobization of MBAM must be applied.

Table 7. Water transport properties.

\begin{tabular}{cccc}
\hline Materials & $A_{w}\left(\mathbf{k g} /\left(\mathbf{m}^{\mathbf{2}} \cdot \mathbf{s}^{\mathbf{1 / 2}}\right)\right)$ & $w_{\text {sat }}\left(\mathrm{kg} / \mathrm{m}^{3}\right)$ & $\kappa_{\text {app }} \times \mathbf{1 0}^{-7}\left(\mathrm{~m}^{\mathbf{2}} / \mathbf{s}\right)$ \\
\hline $\mathrm{M}_{\text {ref }}$ & $0.324 \pm 0.008$ & $341 \pm 5$ & $9.0 \pm 0.6$ \\
MBAM & $0.423 \pm 0.010$ & $433 \pm 6$ & $9.5 \pm 0.6$ \\
\hline
\end{tabular}

The water vapor transition parameters are given in Table 8. As reported by other researchers [60] water vapor transport in case of wet-cup arrangement of the cup test was faster compared to dry-cup test. This can be attributed to filling of pore surface with water molecules what reduced binding forces decelerating water vapor transmission. The MBAM mortar exhibited significantly lower water vapor resistance factor compared to reference material. This was due to its high open porosity. Slightly lower values of water vapor permeability reported, e.g., Barnat-Hunek et al. [61] who tested properties of cement-lime restoration renders produced with zeolite, lightweight aggregate, and boiler slag. This mortar performance is highly promising for its application on damp and salt laden masonry as high water vapor permeability and water vapor diffusion coefficient ensure water vapor evaporation, and thus natural drying of such exposed structures. Moreover, the water vapor resistance factor of MBAM was safely < 15, what is limiting value required by EN 988-1 [62] for repair mortars. In this respect, the use of ternary based binder whose design and testing for application in repair mortars is the main goal of the paper, was quite successful for achievement high water vapor transmission rate of the developed mortar.

Table 8. Water vapor transmission properties.

\begin{tabular}{ccccc}
\hline \multicolumn{2}{c}{ Materials } & $\delta \times \mathbf{1 0}^{-\mathbf{1 1}} \mathbf{( s )}$ & $\boldsymbol{D} \times \mathbf{1 0}^{-\mathbf{6}}\left(\mathbf{m}^{\mathbf{2}} \mathbf{s}\right)$ & $\boldsymbol{\mu}(\mathbf{- )}$ \\
\hline \multirow{2}{*}{ dry-cup } & $\mathrm{M}_{\text {ref }}$ & $1.50 \pm 0.02$ & $2.05 \pm 0.03$ & $12.2 \pm 0.3$ \\
& MBAM & $1.78 \pm 0.03$ & $2.43 \pm 0.04$ & $10.3 \pm 0.2$ \\
\hline \multirow{2}{*}{ wet-cup } & $\mathrm{M}_{\text {ref }}$ & $1.66 \pm 0.02$ & $2.27 \pm 0.04$ & $11.0 \pm 0.2$ \\
& MBAM & $2.10 \pm 0.03$ & $2.87 \pm 0.05$ & $8.7 \pm 0.2$ \\
\hline
\end{tabular}


Mortars thermal properties are presented in Table 9. One must take into consideration, mortar as part of building envelopes contributes significantly to its overall hygrothermal performance. Therefore, its low thermal conductivity and moderate heat capacity are often required in repair works. As expected, high porosity of mortar MBAM reduced its thermal conductivity as well as volumetric heat capacity. The dry thermal conductivity value of MBAM was even more than two times lower compared to that obtained for reference mortar $\mathrm{M}_{\text {ref. }}$ This mortar behavior can find use in design of thermal insulation renders or repair mortars with improved thermal performance. The presence of water increased the both investigated thermal parameters as water has high thermal conductivity and volumetric heat capacity compared to dry air [63]. On similar increase in thermal conductivity with increasing moisture content reported, e.g., Pavlík et al. [64] who tested thermal properties of lime-pozzolan plasters based on waste ceramic powder.

Table 9. Thermal properties.

\begin{tabular}{ccccc}
\hline Materials & $\lambda_{\text {dry }}(\mathrm{W} /(\mathbf{m} \cdot \mathbf{K}))$ & $c_{v d r y} \times \mathbf{1 0}^{\mathbf{6}}\left(\mathrm{J} /\left(\mathbf{m}^{\mathbf{3}} \cdot \mathbf{K}\right)\right)$ & $\lambda_{\text {sat }}(\mathrm{W} /(\mathbf{m} \cdot \mathbf{K}))$ & $c_{v s a t} \times \mathbf{1 0}^{\mathbf{6}}\left(\mathrm{J} /\left(\mathbf{m}^{3} \cdot \mathbf{K}\right)\right)$ \\
\hline $\mathrm{M}_{\text {ref }}$ & $1.10 \pm 0.02$ & $1.60 \pm 0.03$ & $3.29 \pm 0.06$ & $1.89 \pm 0.03$ \\
MBAM & $0.45 \pm 0.008$ & $1.48 \pm 0.03$ & $2.18 \pm 0.04$ & $2.09 \pm 0.04$ \\
\hline
\end{tabular}

Thermal behavior of prepared samples $\mathrm{M}_{\text {ref }}$ and MBAM was tested using STA (see Figure 7). Two major effects were detected for the sample $\mathrm{M}_{\text {ref }}$. The first endothermic effect starting at $\sim 400{ }^{\circ} \mathrm{C}$ is the decomposition of portlandite, during the decomposition water is released as can be seen on the TG curve (weight decrease 3.2\%). The onset temperature of the second endothermic effect was at $\sim 700{ }^{\circ} \mathrm{C}$. This effect was caused because of the decomposition of calcium carbonate. The release of carbon dioxide was clearly visible from the TG curve (weight decrease $13.8 \%$ ). Thermal behavior of the sample MBAM was different: the first exothermic effect was caused due to oxidation of remaining carbon that was resent in biomass ash. This effect was accompanied by a gradual decrease in weight. The second effect, similarly to $\mathrm{M}_{\text {ref, }}$, was caused by the decomposition of calcium carbonate. In this case it was difficult to exactly determine the weight decrease due to the shape of TG curve, decrease was approx. $8.0 \%$. The overall weight decrease of both samples during the heating was comparable.

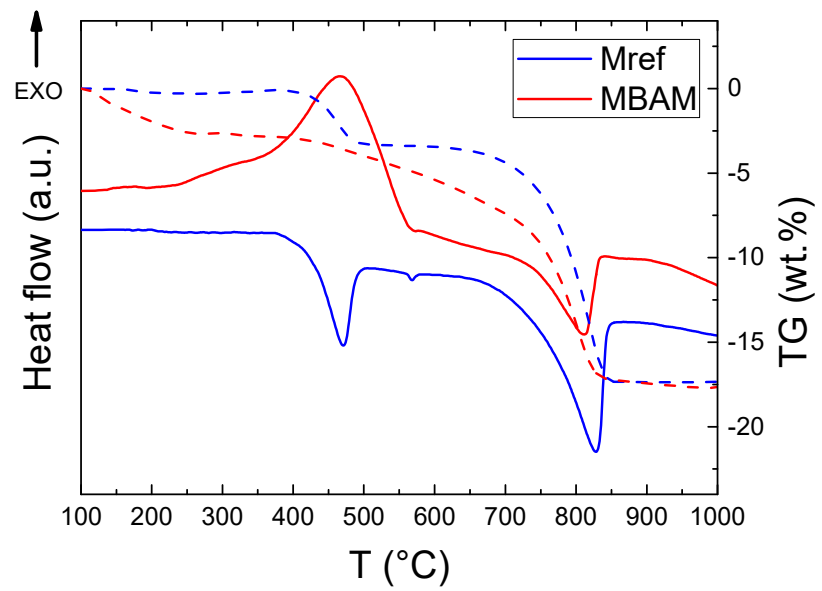

Figure 7. DTA a TG curves of (A) $\mathrm{M}_{\text {ref }}$ and (B) MBAM measured in air atmosphere.

Repair mortars for use in historical building must fulfil compatibility criteria with respect to original materials and qualitative criteria required by technical standards. The conducted experimental campaign aimed at the assessment of a novel type of lime-pozzolan ternary blended binder applied in mortar composition proved that studied material met all considered qualitative criteria for repair mortars. Nevertheless, a satisfactory evaluation of the suitability of the mortars for restoration is quite difficult and specific parameters of materials for repair purposes must be considered case by case 
taking into account properties of original inbuilt materials, their state, range of damage, exterior and interior service conditions.

\section{Conclusions}

In this study, new type of ternary blended binder was studied as possible binding material for production of a novel repair mortar. The ternary binder was mixed from lime hydrate, biomass ash, and metakaolin. On the basis of obtained experimental results, the following conclusions can be drawn:

- Biomass ash and metakaolin contained high content of silica and alumina phases what was positive for their presumed use as active mineral admixtures in mortar mix composition.

- Both alternative binder components exhibited high pozzolanic character and sufficient fineness for their blending with lime hydrate.

- Mortar with ternary blended binder showed decreased bulk density and thus significantly increased porosity. As one of the decisive parameters of repair mortar is their high porosity $(>40 \%)$, the use of ternary blended binder was quite effective in this respect.

- The value of strength activity index was for mortar MBAM high, and gave evidence of great pozzolanic activity of both incorporated mineral admixtures.

- The water vapor resistance factor of mortar MBAM met the criteria required of EU standards for repair mortars.

- The use of ternary blended binder resulted in a significant decrease in the thermal conductivity. Based on that, the developed mortar MBAM can contribute to the improvement of the overall hygrothermal performance of renovated masonry.

As the developed lightweight mortar exhibited good functional performance it can be concluded, the tested biomass ash could potentially represent an eco-efficient low-cost alternative to other pozzolans commonly used in construction industry. Moreover, biomass ash blending with metakaolin and lime hydrate gave binder acceptable by culture heritage authorities for restoration of historical buildings and monuments. Because construction industry suffers from the limited natural resources used for production of building materials, reuse of biomass ash as by product of energy generation in composition of ternary blended binder represents beneficial solution for ash disposal considering circular economy principles. For the practical use of mortar MBAM examined in this paper, it will be necessary to apply water repellents, workability, adhesive, and other additives to adjust its properties for specific rendering and structural purposes. Specific attention must be also paid to the formulation of mortar mix, considering BA and metakaolin dosage, e.g., ratio of lime hydrate replacement, and water/binder ratio. As building practice impose in repair historical buildings complex requirements on material hygrothermal and mechanical performance, the problem of a possible use of lightweight aggregate (perlite, zeolite, pumice, expanded glass granulate, etc.) in mortar composition should be also addressed. In this way, it will be possible to partially improve thermal behavior of repaired buildings without application of any additional thermal insulation systems that are mostly forbidden in historical listed buildings. These analyses, experiments and tests will be the subject of the future applied research that will be necessary before launch the newly developed repair mortar in the market.

Author Contributions: Z.P. and M.P. conceived and designed the experiments; L.Z., M.Z., J.P., and M.L. performed the experiments; Z.P., M.P. and O.J. analyzed the data; O.J. and M.Z. contributed reagents/materials/analysis tools; M.P., Z.P. and O.J. wrote the paper.

Funding: This research was funded by the Czech Science Foundation, under project No 18-07332S—Properties, durability and performance of lightweight mortars with mineral admixtures.

Conflicts of Interest: The authors declare no conflict of interest. 


\section{References}

1. Nogueira, R.; Ferreira Pinto, A.P.; Gomes, A. Design and behavior of traditional lime-based plasters and renders. Review and critical appraisal of strengths and weaknesses. Cem. Concr. Compos. 2018, 89, 192-204. [CrossRef]

2. Callebaut, K.; Elsen, J.; Van Balen, K.; Viane, W. Nineteenh century hydraulic restoration mortars in the Saint Michael's Church (Leuven, Belgium) Natural hydraulic lime or cement? Cem. Concr. Res. 2001, 31, 397-403. [CrossRef]

3. Lea, F.M. The Chemistry of Cement and Concrete; Edward Arnold: London, UK, 1976.

4. Degryse, P.; Elsen, J.; Waelkens, M. Study of ancient mortars from Sagalassos (Turkey) in view of their conservation. Cem. Concr. Res. 2002, 32, 1457-1463. [CrossRef]

5. Borges, C.; Santos Silva, A.; Veiga, R. Durability of ancient lime mortars in humid environment. Constr. Build. Mater. 2014, 66, 606-620. [CrossRef]

6. Ravi, R.; Thirumalini, S.; Taher, N. Analysis of ancient lime plasters-Reason behind longevity of the Monument Charminar, India a study. J. Build. Eng. 2018, 20, 30-41. [CrossRef]

7. Ponce-Antón, G.; Arizzi, A.; Cruz Zuluaga, M.; Cultrone, G.; Ortega, L.A.; Mauleon, J.A. Mineralogical, textural and physical characterization to determine deterioration susceptibility of Irulegi castle lime mortars (Navarre, Spain). Materials 2019, 12, 584. [CrossRef] [PubMed]

8. Grilo, J.; Faria, P.; Veiga, R.; Silva, A.S.; Silva, V.; Velosa, A. New natural hydraulic lime mortars-physical and microstructural properties in different curing conditions. Constr. Build. Mater. 2014, 54, 378-384. [CrossRef]

9. Zhang, D.; Zhao, J.; Wang, D.; Xu, C.; Zhai, M.; Ma, X. Comparative study on the properties of three hydraulic lime mortar systems: Natural hydraulic lime mortar, cement-aerial lime-based mortar ad slag-aerial lime-based mortar. Constr. Build. Mater. 2018, 186, 42-52. [CrossRef]

10. Silva, B.A.; Ferreira Pinto, A.P.; Gomes, A. Natural hydraulic lime versus cement for blended lime mortars for restoration works. Constr. Build. Mater. 2015, 94, 346-360. [CrossRef]

11. Moropoulou, A.; Bakolas, A.; Moundoulas, P.; Aggelakopoulou, E.; Anagnostopoulou, S. Strength development and lime reaction in mortars for repairing historic masonries. Cem. Concr. Res. 2005, 27, 289-294. [CrossRef]

12. Lanas, J.; Pérez Bernal, J.L.; Bello, M.A.; Alvarez Galindo, J.I. Mechanical properties of natural hydraulic lime-based mortars. Cem. Concr. Res. 2004, 34, 2191-2201. [CrossRef]

13. Mosquera, M.J.; Silva, B.; Prieto, B.; Ruiz-Herrera, E. Addition of cement to lime-based mortars: Effect on pore structure and vapor transport. Cem. Concr. Res. 2006, 36, 1635-1642. [CrossRef]

14. Faria-Rodrigues, P.; Henriques, F.M.A. Current mortars in conservation: An overview. Restor. Build. Monum. 2004, 10, 609-622.

15. Elert, K.; Rodriguez-Navarro, C.; Pardo, E.; Hansen, H.; Cazalla, O. Lime mortars for the conservation of historic buildings. Stud. Conserv. 2002, 47, 62-75. [CrossRef]

16. Barbero-Barrera, M.; Maldonado-Ramos, L.; Van Balenb, K.; García-Santosa, A.; Neila-González, F. Lime render layers: An overview of their properties. J. Cult. Herit. 2014, 15, 326-330. [CrossRef]

17. Schueremans, L.; Cizer, Ö.; Janssens, E.; Serré, G.; Van Balen, K. Characterization of repair mortars for the assessment of their compatibility in restoration projects: Research and practice. Constr. Build. Mater. 2011, 25, 4338-4350. [CrossRef]

18. Arrizi, A.; Viles, H.; Cultrone, G. Experimental testing of the durability of lime-based mortars used for rendering historic buildings. Constr. Build. Mater. 2012, 28, 807-818. [CrossRef]

19. Hendry, A.W. Masonry walls: Materials and construction. Constr. Build. Mater. 2001, 15, 323-330. [CrossRef]

20. Lubelli, B.; Nijland, T.G.; van Hees, R.P.J.; Hacquerbord, A. Effect of mixed in crystallization inhibitor on resistance of lime-cement mortar against $\mathrm{NaCl}$ crystallization. Constr. Build. Mater. 2010, 24, 2466-2472. [CrossRef]

21. Lanas, J.; Sirera, R.; Alvarez, J.I. Study of the mechanical behavior of masonry repair lime-based mortars cured and exposed under different conditions. Cem. Concr. Res. 2006, 36, 961-970. [CrossRef]

22. Mosquera, M.J.; Benitez, D.; Perry, S.H. Pore structure in mortars applied on restoration: Effects on properties relevant to decay of granite buildings. Cem. Concr. Res. 2002, 32, 1883-1888. [CrossRef]

23. Arandigoyen, M.; Alvarez, J.I. Pore structure and mechanical properties of cement-lime mortars. Cem. Concr. Res. 2007, 37, 767-775. [CrossRef] 
24. Arandigoyen, M.; Alvarez, J.I. Blended pastes of cement and lime: Pore structure and capillary porosity. Appl. Surf. Sci. 2006, 252, 8077-8085. [CrossRef]

25. Záleská, M.; Pavlík, Z.; Pavlíková, M.; Scheinherrová, L.; Pokorný, J.; Trník, A.; Svora, P.; Fořt, J.; Jankovský, O.; Suchorab, O.; et al. Biomass ash-based mineral admixture prepared from municipal sewage sludge and its application in cement composites. Clean Technol. Environ. Policy 2018, 20, 159-171. [CrossRef]

26. Donatello, S.; Tyrer, M.; Cheeseman, C.R. Comparison of test methods to assess pozzolanic activity. Cem. Concr. Compos. 2010, 32, 121-127. [CrossRef]

27. Chia-Jung, T.; Ran, H.; Wei-Ting, L.; His-Ning, W. Mechanical and cementitious characteristics of ground granulated blast furnace slag and basic oxygen furnace slag blended mortar. Mater. Des. 2014, 60, 267-273. [CrossRef]

28. Borges, A.; Flores-Colen, I.; de Brito, J. Physical and mechanical performance of cement-based renders with different contents of fly ash, expanded cork granules and expanded clay. Constr. Build. Mater. 2018, 191, 535-543. [CrossRef]

29. Balbuena, J.; Sínchez, L.; Cruy-Yusta, M. Use of steel industry wastes for the preparation of self-cleaning mortars. Materials 2019, 12, 621. [CrossRef]

30. Sala, E.; Giustina, I.; Plizzari, G.A. Lime mortar with natural pozzolana: Historical issues and mechanical behaviour. In Structural Analysis of Historic Construction; D'Ayala, D., Fodde, E., Eds.; Taylor \& Francis Group: London, UK, 2008; pp. 957-963.

31. Pavia, S.; Aly, M. Influence of aggregate and supplementary cementitious materials on the properties of hydrated lime (CL90s) mortar. Mater. Constr. 2016, 66, e104. [CrossRef]

32. Ulukaya, S.; Yuzer, N. Assessment of pozzolanicity of clay bricks fired at different temperatures for use in repair mortar. J. Mater. Civ. Eng. 2016, 28, 04015052. [CrossRef]

33. Stefanidou, M. Use of natural pozzolans with lime for producing repair mortars. Environ. Earth Sci. 2016, 75, 758. [CrossRef]

34. Pavlíková, M.; Zemonová, L.; Pokorný, J.; Záleská, M.; Jankovský, O.; Lojka, M.; Sedmidubský, D.; Pavlík, Z. Valorization of wood chips ash as an eco-friendly mineral admixture in mortar mix design. Waste Manag. 2018, 80, 89-100. [CrossRef]

35. Sklivaniti, V.; Tsakiridis, P.E.; Katsiotis, N.S.; Velissariou, D.; Pistofidis, N.; Papageorgiou, D.; Beazi, M. Valorisation of woody biomass bottom ash in Portland cement: A characterization and hydration study. J. Environ. Chem. Eng. 2017, 5, 205-213. [CrossRef]

36. Salvo, M.; Rizzo, S.; Caldirola, M.; Novajra, G.; Canonico, F.; Bianchi, M.; Ferraris, M. Biomass ash as supplementary cementitious material (SCM). Adv. Appl. Ceram. 2015, 114, 3-10. [CrossRef]

37. El-Diadamony, H.; Amer, A.A.; Sokkary, T.M.; El-Hoseny, S. Hydration and characterisitcs of metakaolin pozzolanic cement pastes. HBRC J. 2016, 14, 150-158. [CrossRef]

38. Nunes, C.; Mácová, P.; Frankeová, D.; Ševčík, R.; Viani, A. Influence of linseed oil on the microstructure and composition of lime and lime-metakaolin pastes after a long curing time. Constr. Build. Mater. 2018, 189, 787-796. [CrossRef]

39. Bakolas, A.; Aggelakopoulou, E.; Moropoulou, A.; Anagnostopoulou, S. Evaluation of pozzolanic activity and physicomechanical characteristics in metakaolin-lime pastes. J. Therm. Anal. Calorim. 2006, 84, 157-163. [CrossRef]

40. Aggelakopoulou, E.; Bakolas, A.; Moropoulou, A. Properties of lime-metakolin mortars for the restoration of historic masonries. Appl. Clay Sci. 2011, 53, 15-19. [CrossRef]

41. Methods of Testing Cement-Part. 6: Determination of Fineness; EN 196-6; European Committee for Standardization: Brussels, Belgium, 2010.

42. Pozzolanic Addition for Concrete-Metakaolin. Definitions, Specifications and Conformity Criteria; NF P 18-513; Association Française de Normalisation: La Plaine Saint-Denis, France, 2010.

43. Methods of Test for Mortar for Masonry_Part. 10: Determination of Dry Bulk Density of Hardened Mortar; EN 1015-10; European Committee for Standardization: Brussels, Belgium, 2000.

44. Methods of Test for Mortar for Masonry_Part. 10: Determination of Flexural and Compressive Strength of Hardened Mortar; EN 1015-11; European Committee for Standardization: Brussels, Belgium, 1999.

45. Fly Ash for Concrete-Part. 1: Definition, Specifications and Conformity Criteria; EN 450-1; European Committee for Standardization: Brussels, Belgium, 2012. 
46. Záleská, M.; Pavlíková, M.; Pavlík, Z.; Jankovský, O.; Pokorný, J.; Tydlitát, V.; Svora, P.; Černý, R. Physical and chemical characterization of technogenic pozzolans for the application in blended cements. Constr. Build. Mater. 2018, 16, 106-116. [CrossRef]

47. Hall, C. Water sorptivity of mortars and concretes: A review. Mag. Concr. Res. 2002, 41, 51-61. [CrossRef]

48. Methods of Test for Mortar for Masonry_Part. 18: Determination of Water-Absorption Coefficient Due to Capillary Action of Hardened Mortar; EN 1015-18; European Committee for Standardization: Brussels, Belgium, 2002.

49. Kumaran, M.K. Moisture diffusivity of building materials from water absorption measurements. J. Therm. Env. Build. Sci. 1999, 22, 349-355. [CrossRef]

50. Hygrothermal Performance of Building Materials and Products-Determination of Water Vapor Transmission Properties; ISO 12572; International Organization for Standardization: Geneva, Switzerland, 2001.

51. Raverdy, M.; Brivot, F.; Paillére, A.M.; Dron, R. Appréciation de I'Activité Pouzzolanique des Constituants Secondaires. In Proceedings of the 7th International Congress on the Chemistry of Cement, Paris, France, 1980; Volume 3, pp. 36-41.

52. Martins, C.H.; de Castro, T.R.; Gallo, C.C. Characterization of mixed mortars with partial replacement of sand with sugarcane bagasse ash (SCBA). Open J. Civ. Eng. 2016, 6, 410-419. [CrossRef]

53. Collepardi, M. Degradation and restoration of masonry walls of historical buildings. Mater. Struct. 1990, 23, 81-102. [CrossRef]

54. Bianco, N.; Calia, A.; Denotarpietro, G.; Negro, P. Hydraulic mortar and problems related to the suaitabilitz for restoration. Periodico Mineral. 2013, 82, 529-542. [CrossRef]

55. Robert, L.; Burwell, J.R. Manual of symbols and terminology for physicochemical quantities and units, appendix II: Definitions, Terminology and Symbols in Colloid and Surface Chemistry-Part I. Pure Appl. Chem. 1976, 46, 71-90. [CrossRef]

56. Aligizaki, K.K. Pore Structure of Cement-Based Materials: Testing, Interpretation, and Requirements; Bentur, A., Mindess, S., Eds.; Modern Concrete Technology Series; CRC Press: New York, NY, USA, 2006.

57. Santos, A.R.; do Rosário Weiga, M.; Silva, A.S.; de Brito, J.; Álvarez, J.I. Evolution of the microstructure of lime based mortars and influence on the mechanical behavior: The role of the aggregates. Constr. Build. Mater. 2018, 187, 907-922. [CrossRef]

58. Valverde, J.M.; Perejon, A.; Medina, S.; Perez-Maquedad, L.A. Thermal decomposition of dolomite under $\mathrm{CO}_{2}$ : Insights from TGA and in isute XRD analysis. Phys. Chem. Chem. Phys. 2015, 17, 30162-30176. [CrossRef] [PubMed]

59. Westgate, P.; Ball, R.J.; Paine, K. Olivine as a reactive aggregate in lime mortars. Constr. Build. Mater. 2019, 195, 115-126. [CrossRef]

60. Roels, S.; Carmeliet, J.; Hens, H.; Adan, O.; Brocken, H.; Cerny, R.; Pavlik, Z.; Hall, C.; Kumaran, K.; Pel, L.; Plagge, R. Interlaboratory comparison of hygric properties of porous building materials. J. Therm. Envelope Build. Sci. 2004, 27, 307-325. [CrossRef]

61. Barnat-Hunek, D.; Siddique, R.; Klimek, B.; Franus, M. The use of zeolite, lightweight aggregate and boiler slag in restoration renders. Constr. Build. Mater. 2017, 142, 162-174. [CrossRef]

62. Specification for Mortar for Masonry_Part. 1: Rendering and Plastering Mortar; EN 998-1; European Committee for Standardization: Brussels, Belgium, 2016.

63. Jiřičková, M.; Pavlík, Z.; Fiala, L.; Černý, R. Thermal properties of mineral wool materials partially saturated by water. Int. J. Thermophys. 2006, 27, 1214-1227. [CrossRef]

64. Pavlík, Z.; Čáchová, M.; Vejmelková, E.; Korecký, T.; Fořt, J.; Pavlíková, M.; Černý, R. Thermal properties of lime-pozzolan plasters for application in hollow bricks systems. Int. J. Civ. Environ. Eng. 2013, 7, 823-827.

(C) 2019 by the authors. Licensee MDPI, Basel, Switzerland. This article is an open access article distributed under the terms and conditions of the Creative Commons Attribution (CC BY) license (http://creativecommons.org/licenses/by/4.0/). 